\title{
Reflecting on Practice: Embedding Student Engagement through Interdepartmental Partnership
}

\author{
Catherine McConnell, University of Brighton
}

\section{Introduction}

The Student Engagement Group (SEG) at the University of Brighton was established in 2015, to enable partnership working between three key stakeholder departments for student engagement - the Centre for Learning and Teaching, Brighton Students' Union and Quality and Standards. The original purpose of the group was to coordinate student engagement in quality processes, as set out by the Quality Assurance Agency for Higher Education (QAA) Quality Code Chapter B5 (2012), and develop an understanding of how best to work with students as partners in learning and teaching (Healey et al, 2014).

In parallel to the formation of the SEG, the national REACT project's call for the Collaborative Development Programme offered an opportunity to join a national community of practice and to develop understanding of 'hard-to-reach' student groups, the better to meet the needs of students within the institutional context. Identifying those students 'hard to reach' at Brighton has proved challenging, often with different classifications emerging from different disciplines. However, institutional commitment to inclusive practice is evident and this project has raised awareness of the need to revisit definitions of 'hard to reach' on an annual basis. The University of Brighton has several student partnership schemes that echo the core values and activities held and followed by REACT. There is an established peer assisted learning scheme (PASS) and, through participating in the REACT project, the SEG was keen to investigate the opportunities further, as Cook-Sather et al (2014) propose, for building capacity for staff-student collaboration on educational research and enhancement. This case study paper first outlines the institutional context and maps the processes and practices that have led to current developments of a strategic document setting out the vision for student engagement at Brighton. Next, an explanation is given of the specifications of the project to embed student engagement across the university, through a partnership network. Finally, a team reflection is offered on the stages of implementation, current progress, and the lessons learnt along the way.

Whilst this paper does not focus upon the case studies of student engagement activities that have been collected as part of the project, these can be found on our institutional blog: www.blogs.brighton.ac.uk/reactbrighton

\section{Institutional Context}

The drive to coordinate student engagement activity at Brighton arose out of growing areas of localised departmental practice, which had emerged through the work of keen practitioners, early adopters and those tasked with enhancing the student experience. This could be described as a grass roots movement, whereby exciting and authentic student engagement was being developed in context, but by a select number of staff and for a few fortunate students. Among other policy mandates created at the time, the QAA Quality Code Chapter B5 (QAA, 2012) gave an external impetus for a more structured approach to student engagement. Following a QAA review visit in 2013, the university's Student Engagement in Quality Steering Group created a "Student Engagement in Quality Policy" (University of Brighton, 2013). This document set out a number of baseline activities that the University and its ten Schools are supposed to deliver in order to facilitate the engagement of students in Quality Assurance procedures. Consequently, the grass-roots student engagement enthusiasts occupied one sphere of institutional engagement at one end of a spectrum and the policy-driven procedural projects were at the other. 
The Student Engagement in Quality Policy was developed to map existing practice to the QAA quality code and identify gaps, but this appeared to highlight the overlap between student engagement in quality processes and engagement in learning and teaching, and left this undefined as there was no mechanism for capturing these activities institutionally. The policy emphasised the importance of partnerships, but, on reflection, there were few opportunities for partnerships between quality, learning and teaching enhancement, and the work of the Students' Union on representation and democracy. An early interdepartmental partnership approach saw the Students' Union and Quality and Standards team working together to write a 'Student Representation Policy' (Brighton Students' Union, 2012). This required each of the ten Schools to identify a senior member of staff to act as the Course Rep. Coordinator, in an attempt to recruit rep.s successfully, through democratic processes, and to ensure that they are supported in their role. Beyond specific time-bound projects such as the student representation policy, inter-departmental partnership efforts were occluded by a lack of definition, boundaries and authority to give mandate to the area of student engagement work.

In order to address the need for coordination and cohesion of student engagement work, and in addition to Brighton's participation in the REACT project, several structural changes were instigated in 2015 that have enabled inter-departmental partnership:

- The establishment of an Engagement and Information team with the Quality and Standards department, within Academic Services (Registry);

- The adoption of student engagement in learning and teaching by the Student Academic Success and Partnership team located within the Centre for Learning and Teaching;

- The instigation of regular partnership team meetings between the Engagement and Information team, Centre for Learning and Teaching, and Students' Union representatives;

- The formation of the Student Engagement Group (SEG), sponsored by the Pro-Vice Chancellor for Education and Student Experience and chaired by a Director of Education;

- The creation of a role specification for a "Student Engagement Champion" with such champions to be based in each of the ten Schools and in twelve Professional Service departments.

The Uiversity has subsequently launched its five-year strategic plan for the period 2016 to 2021, pledging to be putting students at the heart of everything we do, aspiring to become "... a learning community of students, staff and partners - a community where learning, teaching, research and practice are equally valued and mutually enhancing." (Practical Wisdom, 2016 - 2021).

This overarching strategy promises to broaden and deepen student involvement across the University through the development of a "Student Engagement Plan" (SE Plan), driven by a dedicated member of senior management and formulated in consultation with students and staff. This SE Plan will provide a platform for developing cultures and practices of student engagement across all facets of university life, facilitating the coordination, celebration and evaluation of student engagement across the University.

\section{Creating a partnership network}

Through the collective expertise of the SEG and the establishment of a network of Student Engagement Champions, the group moved towards a shared definition of student engagement at Brighton, situating student engagement in co- and extra-curricular activities, in order to improve opportunities for students' active participation and to build learning 
communities. This collective approach has provided a constructive forum to share knowledge and understanding, which informs the development of the Student Engagement Plan and resulting practices.

Recruiting School-based Student Engagement Champions has provided an opportunity for the SEG to talk with Schools about contextualised student engagement activity. A member from each department represented by the SEG visited every School to talk with the Champion and to collect ideas for case studies that capture and showcase student engagement activities. Within each School, subject disciplines have different cultures and challenges and the SEG has recognised that the level of student engagement activity varies. Extending the Champion role to Professional Services departments has been crucially successful in raising the importance of student engagement and embedding awareness of practices across the institution. The Champions form a wider network for this partnership, and a continuing resource for collaborative working in the future.

\section{Student Engagement Champion role specification}

A nominated Student Engagement Champion is a member of staff at a senior level with a remit integrated into her/his existing workload and is responsible for developing student engagement in her/his own context, i.e. to reflect that context's particular characteristics, discipline and structures. The Champion:

1. fosters student engagement within the School/Support Service, often initiating the development and enhancement of student engagement activities within her/his School/Support Service;

2. acts as a key point of contact for staff and students in her/his School/Support Service for information and advice about student engagement, including policies and resources available;

3. encourages staff and student interest in student engagement in the School/Support Service through promoting opportunities for this and supports staff and student collaborative working;

4. works in partnership with Course Rep.s and the School Academic Rep. to support and develop student engagement activities within the School and encourages other students to share their views and ideas.

5. supports and promotes the implementation of the University's Student Engagement in Quality Policy, including: the effective operation of the Course Rep. system (working with the Course Rep. Coordinator and Course Leaders); the collection of student feedback; closing the feedback loop;

6. supports the Students' Union, Quality and Standards, and Learning and Teaching in training for staff and students on student engagement and in monitoring and reviewing student engagement activities across Schools/Support Services;

7. helps to document the ways in which the School/Support Service engages with students and shares successful student engagement practice in both the School/Support Service and the wider university community, in order to help build sustainable student engagement processes.

\section{Networking and events}

A range of resources and events has been created for the network of Champions, to assist them in their role and develop a platform for sharing practice. A private, shared, online space has enabled the SEG to post announcements (such as a termly newsletter to welcome new Champions), showcase examples of activities and link to a calendar of local and national student-engagement events. The SEG has also put links to newly-published articles and books of interest to the community and encourages members to share their research and 
practice. The online forum supports a face-to-face schedule of events, consisting of a Champions REACT away-day, a termly two-hour workshop programme and any requested one-to-one meetings with each Champion.

\section{Lessons learnt}

As part of the reflective methodology in documenting this case study of practice, SEG members shared individual reflections on their experiences of inter-departmental partnership working, highlighting the advantages and challenges that have been faced along the way.

"[This partnership] is a new stance for me, as although I have worked with many other departments this was the first shared cross-departmental project where we had a common goal and used our combined expertise to impact on student engagement." (Quality and Standards Officer, Engagement and Information)

"The group has been able to promote student engagement in the university to some extent in order to start encouraging a culture change at the university; however, the pace of this change has been slow and at times frustrating." (Quality and Standards Manager, Engagement and Information)

"The challenges of inter-department partnership working I think are compounded by the amount of time we are able to devote to the tasks we have set ourselves. Our ambition has been high, but sometimes I feel disappointed that we are not able to make as much progress as we would like." (Student Academic Success and Partnership Lead, Centre for Learning and Teaching)

"The benefits of working across the three divisions has been that it's shown senior management there is a ground-level appetite for this work and it's shown that three traditionally separate divisions can work well together." (Student Community Project Manager, Brighton Students' Union)

"Other challenges arise when staff who we are working with are promoted, or change roles, as new Champions may have different interpretations of engagement and partnership, or need inducting, and the process begins again." (Student Academic Success and Partnership Lead, Centre for Learning and Teaching)

"The challenges of inter-department partnership working are most apparent when there's a lack of leadership. The group was able to make practical changes but wasn't able to progress at pace or consider its actions in a broader context which made future-proofing or future-planning difficult." (Student Community Project Manager, Brighton Students' Union)

"The experience has been very rewarding and equally frustrating. It has been slow to gain importance and momentum within schools and departments. It has been a little frustrating as the team relies on a lot of 'good will' both of individuals in the team and of Student Engagement Champions." (Quality and Standards Officer, Engagement and Information)

"I was interested to learn more about student engagement activity 'outside' of quality assurance. Student engagement is not well defined in the university but there needs to be co-ownership of the process and sharing of ideas." (Quality and Standards Officer, Engagement and Information)

\section{Discussion and next steps}


The Student Engagement Group (SEG) has faced the difficult task of contributing to a change in culture across the University, particularly framed against structural shifts in Higher Education, adaptation to a new institutional strategy and increasing demands on Schools and Departments for planning, monitoring and responding to feedback in order to improve their services. The challenges of inter-departmental partnership working are most apparent when there is a lack of steer or senior leadership; nevertheless, the group has been able to take practical steps towards a networked and embedded approach. The benefits of working across the three divisions have been the demonstration to institutional leaders of a groundlevel appetite for student engagement work, and how three traditionally separate divisions can work well together to affect a collective transformation in policy and practice.

Beyond the REACT project, and in the next phase of embedding and expanding the partnership network, the SEG is acutely aware that the voice and representation of students in the group is missing. Robinson (2012) reminds us that

"...students should be able to develop an understanding of themselves as partners with staff in the process of improving the quality of their HEl experiences..."

In order to address this recommendation, the SEG is focusing efforts on the evolution of a 'School Academic Representative', which will see at least two current students per School in paid employment in the role, working in parallel with Student Engagement Champions. Student membership of the group is of priority, as is developing training and materials that can help staff and students work in partnership to engender mutual understandings that, in turn, facilitate joint enhancement of higher education practices.

\section{Reference list}

Brighton Students' Union (2012) Student Representation Policy. Internal document. Cook-Sather, A., Bovill, C. and Felten, P. (2014) Engaging Students as Partners in Learning and Teaching: A Guide for Faculty. San Francisco: Jossey-Bass.

Healey, M., Flint, A. and Harrington, K. (2014) Engagement through partnership: Students as partners in learning and teaching in higher education. York: The Higher Education Academy.

Quality Assurance Agency [QAA] (2012) 'Student engagement.' In: UK Quality Code for Higher Education. Gloucester: The Quality Assurance Agency for Higher Education, Chapter B5.

Robinson, C. (2012) 'Student engagement: What does this mean in practice in the context of higher education institutions?' Journal of Applied Research in Higher Education, 4, 94-108.

University of Brighton (2013) Student Engagement in Quality Policy. Internal document.

University of Brighton (2016) Practical Wisdom - University Strategy 2016-2021. Available at: https://staff.brighton.ac.uk/mac/public docs/University-Strategy-2016-2021.pdf (Accessed: 12 June 2017). 